\title{
A Relative Reliability Approach for Direct Displacement-Based Seismic Design of Partially Prestressed Reinforced Concrete Frame Structures
}

\author{
Bin Jian, Chaoyi Lei, and Pingping Liao \\ Institute of Civil Engineering, Chongqing University, Chongqing 400045, China \\ Correspondence should be addressed to Bin Jian; bjian@cqu.edu.cn
}

Received 18 June 2015; Revised 1 August 2015; Accepted 2 August 2015

Academic Editor: David Bigaud

Copyright (C) 2015 Bin Jian et al. This is an open access article distributed under the Creative Commons Attribution License, which permits unrestricted use, distribution, and reproduction in any medium, provided the original work is properly cited.

\begin{abstract}
A relative reliability approach for Direct Displacement-Based Design (DDBD) is first proposed in this paper, which is based on the average reliability level implicit in current Chinese design codes. By introducing a relative reliability coefficient $\alpha$, the determination of reliability from DDBD is transformed to the calculation of its ratio to the average reliability of current Chinese codes. This approach not only follows the reliability principle of current Chinese codes, but also avoids the complex calculation of reliability in general. The calculation of reliability at any performance level can be transformed to the nominal reliability of frequent earthquake for the expected earthquake risk level. Meanwhile, based on the assumption of elasticity, it is shown that, under frequent earthquake risk, the calculated base shear derived from DDBD theoretically equals that from force-based design (FBD). Therefore, a revised calculation of section bearing capacity for DDBD, which follows the expression in current Chinese codes, is advised, according to the numerical study of 24 examples of Partially Prestressed Reinforced Concrete (PPRC) frame structures. Finally, this proposed approach is verified to be effective and superior by a comparative analysis of 10 examples of PPRC frames.
\end{abstract}

\section{Introduction}

Real seismic response of structures shows that a traditional force-based seismic approach is difficult to accord with the expected structural displacement under the designed earthquake risk. Towards this, Displacement-Based Seismic Design (DBSD) was proposed and extensively studied in the last decades.

Nowadays, DBSD has been developed and employed in various structures. In 1995, a DDBD method [1] was presented for bridge design; after that, Priestley suggested the improved DDBD method applied to Reinforced Concrete (RC) structures [2, 3]. In 2009 a model code for the Displacement-Based Seismic Design of Structures (DBD09) was first proposed by Calvi and Sullivan [4] and the latest revised vision was published in 2012 [5]. Liang et al. developed this method for seismic design of RC frame structures [6]. Moreover, DDBD has been effectively applied to frameshear wall structures [7], glued timber structures [8], and steel eccentrically braced frame structures [9], and so forth. Malekpour and Dashti also provided the specific design procedures of DDBD for different types of RC buildings [10]. All research work above is significant to develop and improve DDBD approaches. However, many problems still have to be solved for an easy application. One of the key problems is how to establish an effective reliability system in DDBD.

According to statistical analysis, Gao et al. pointed out that, under the confidence 0.05 or 0.1 , the ultimate drift ratio of a RC frame obeys a lognormal distribution or an extreme I distribution. They also studied the seismic reliability of ultimate deformation capacity of RC frames under rare earthquake risk [11, 12]. In 2002, a probabilistic description was proposed for the DBSD method [13]. To reveal the reliability level of drift ratios on the weak floor, the maximum elastoplastic displacement and ultimate drift ratio of RC frames was characterized by probability [14]. In 2013, reliability comparative analysis [15] was conducted in two 24 -story buildings, based on the traditional seismic design 
and performance-based seismic design, respectively. Analysis results indicate that less weight and higher reliability can be found in performance-based seismic design. Furthermore, work by Welch et al. (2014) and Sullivan et al. (2014) has investigated the introduction of probabilistic considerations within the Direct DBD or Displacement-Based Assessment (DBA) procedures $[16,17]$.

The current studies on reliability approaches for DDBD are useful to instruct seismic design. However, the complete reliability theoretical system is still not established. Influences of structural reliability may differ from one analysis to another, and it is difficult to precisely determine them, such as variation coefficients, $e$. Moreover, complex derivation and excessive assumptions probably lead to large calculation errors in design. Towards these problems, in this paper, a relative reliability (relative to the average reliability implicit in current Chinese codes $[18,19])$ approach is first proposed for DDBD, without a complex calculation of variation coefficients in the reliability analysis.

\section{The Relative Reliability Approach for DDBD}

The function $Z$ of structural reliability can be written as $Z=R-S$, where $R$ is the resistance corresponding to the given performance target, while $S$ is the effect under expected earthquake risk level. If both $R$ and $S$ obey the lognormal distribution described by the maximum drift ratio of structure at performance target, the reliability index can be expressed as

$$
\beta=\frac{\mu_{\ln R}-\mu_{\ln S}}{\sqrt{\sigma_{\ln R}^{2}+\sigma_{\ln S}^{2}}},
$$

where $\mu_{\ln R}, \mu_{\ln S}$ and $\sigma_{\ln R}, \sigma_{\ln S}$ denote the mean and the standard deviation of $\ln R$ and $\ln S$, respectively.

To assess the reliability in DDBD effectively, it is necessary to calculate the correlation standard deviation of the resistance and the effect of structure precisely, according to variation coefficients.

\subsection{Philosophy of Relative Reliability Approach in DDBD}

2.1.1. Nominal Reliability $\beta_{A}$ under Frequent Earthquake Risk. To establish the reliability approach for DDBD, evaluation of reliability at the given performance target is first transformed to the expected seismic risk level under frequent earthquake risk, while the section bearing capacity of structure is determined by a similar way as FBD. For instance, in Figure 1, point $A$ and point $B$ denote the displacement at performance point (effect $S$ ) under frequent earthquake risk and rare earthquake risk, respectively. Point $C$ is the displacement corresponding to life safety level (resistance $R$ ). According to the suggested design philosophy, calculation of reliability at point $B\left(\beta_{B}\right)$ will be first transformed to the determination of reliability at point $A$, namely, nominal reliability $\left(\beta_{A}\right)$. Then the seismic effect under frequent earthquake risk can be derived from $\beta_{A}$ for the performance target under rare earthquake risk. Once a structure is designed by FBD under Chinese codes, its pushover curve will be attained (see Figure 1). In this case,

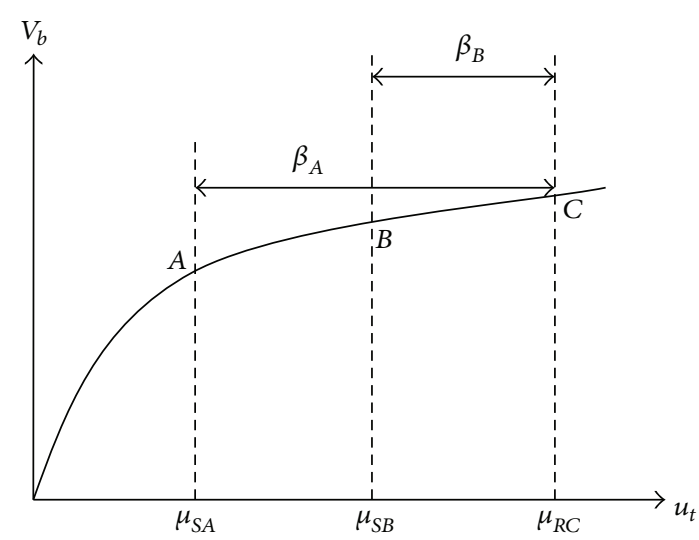

FIgURE 1: Theory of the method.

the mapping relationship between $\beta_{B}$ and $\beta_{A}$ can be found based on the current seismic design under frequent earthquake risk. That means a structure designed by the nominal reliability under frequent earthquake risk $\beta_{A}$ can generally satisfy the demand from the real reliability under performance target $\beta_{B}$. An illustration for this relationship has been provided as follows.

As shown in Figure $1, \mu_{S A}, \mu_{S B}$, and $\mu_{R C}$ denote the average displacement corresponding to the frequent earthquake risk, rare earthquake risk, and resistance under rare earthquake risk, respectively. It has been shown that all displacements of effect $S$ or resistance $R$ at point $A$, point $B$, and point $C$ obey a lognormal distribution [20]; therefore

$$
\begin{gathered}
\beta_{A}=\frac{\ln \left(\left(\mu_{R C} / \mu_{S A}\right) \sqrt{\left(1+\delta_{S A}^{2}\right) /\left(1+\delta_{R C}^{2}\right)}\right)}{\sqrt{\ln \left[\left(1+\delta_{R C}^{2}\right)\left(1+\delta_{S A}^{2}\right)\right]}}, \\
\beta_{A B}=\frac{\ln \left(\left(\mu_{S B} / \mu_{S A}\right) \sqrt{\left(1+\delta_{S A}^{2}\right) /\left(1+\delta_{S B}^{2}\right)}\right)}{\sqrt{\ln \left[\left(1+\delta_{S B}^{2}\right)\left(1+\delta_{S A}^{2}\right)\right]}}, \\
\beta_{B}=\frac{\ln \left(\left(\mu_{R C} / \mu_{S B}\right) \sqrt{\left(1+\delta_{S B}^{2}\right) /\left(1+\delta_{R C}^{2}\right)}\right)}{\sqrt{\ln \left[\left(1+\delta_{R C}^{2}\right)\left(1+\delta_{S B}^{2}\right)\right]}} .
\end{gathered}
$$

Thus, the relationship between $\beta_{A}$ and $\beta_{B}$ can be given as

$$
\beta_{A}=a \cdot \beta_{B}+b \cdot \beta_{A B},
$$

where coefficients $a$ and $b$ satisfy

$$
\begin{aligned}
& a=\frac{\sqrt{\ln \left[\left(1+\delta_{R C}^{2}\right)\left(1+\delta_{S B}^{2}\right)\right]}}{\sqrt{\ln \left[\left(1+\delta_{R C}^{2}\right)\left(1+\delta_{S A}^{2}\right)\right]}}, \\
& b=\frac{\sqrt{\ln \left[\left(1+\delta_{S B}^{2}\right)\left(1+\delta_{S A}^{2}\right)\right]}}{\sqrt{\ln \left[\left(1+\delta_{R C}^{2}\right)\left(1+\delta_{S A}^{2}\right)\right]}} .
\end{aligned}
$$

In theory, due to the lognormal distribution of $S$ and $R$, the value of coefficient can be determined. The mean of 
structural effect, which reflects the value of $\beta_{A B}$, will be accordingly certainty. Thus, the relationship between $\beta_{A}$ and $\beta_{B}$ is unique. In real calculation, different methods lead to different deviation coefficients, while the values of deviation coefficients will be stable at both elastic and elastoplastic stages, once the methods follow the same seismic design [20]. In this case, the value of reliability $\beta_{B}$ can be reasonably derived from the nominal reliability $\beta_{A}$.

2.1.2. Relative Reliability Coefficient $\alpha$. To determine the nominal reliability $\beta_{A}$, a relative reliability coefficient $\alpha$ is introduced. If the effect $S$ is defined by the maximum story drift ratio corresponding to structural performance point under frequent earthquake risk and the resistance $R$ the maximum story drift ratio of the expected failure state of structure under the performance target, the reliability can be expressed by

$$
\begin{aligned}
\beta_{1} & =\frac{\ln \left(\left(\mu_{R 1} / \mu_{S 1}\right) \sqrt{\left(1+\delta_{S 1}^{2}\right) /\left(1+\delta_{R 1}^{2}\right)}\right)}{\sqrt{\ln \left[\left(1+\delta_{R 1}^{2}\right)\left(1+\delta_{S 1}^{2}\right)\right]}} \\
= & \frac{\ln \left(\mu_{R 1} / \mu_{S 1}\right)+\ln \left(\sqrt{\left(1+\delta_{S 1}^{2}\right) /\left(1+\delta_{R 1}^{2}\right)}\right)}{\sqrt{\ln \left[\left(1+\delta_{R 1}^{2}\right)\left(1+\delta_{S 1}^{2}\right)\right]}} .
\end{aligned}
$$

Compared to $\ln \left(\mu_{R 1} / \mu_{S 1}\right), \ln \left(\sqrt{\left(1+\delta_{S 1}^{2}\right) /\left(1+\delta_{R 1}^{2}\right)}\right)$ is a smaller value and can be neglected; thus

$$
\begin{aligned}
\beta_{1} & =\frac{\ln \left(\left(\mu_{R 1} / \mu_{S 1}\right) \sqrt{\left(1+\delta_{S 1}^{2}\right) /\left(1+\delta_{R 1}^{2}\right)}\right)}{\sqrt{\ln \left[\left(1+\delta_{R 1}^{2}\right)\left(1+\delta_{S 1}^{2}\right)\right]}} \\
& =\frac{\ln \left(\mu_{R 1} / \mu_{S 1}\right)}{\sqrt{\ln \left[\left(1+\delta_{R 1}^{2}\right)\left(1+\delta_{S 1}^{2}\right)\right]}},
\end{aligned}
$$

where $S 1$ is the maximum story drift ratio of structure at the performance point under frequent earthquake risk and $R 1$ the maximum story drift ratio of the expected failure state of structure under the performance target. Correspondingly, the mean and the deviation coefficients can then be given as $\mu_{R 1}, \mu_{S 1}$ and $\delta_{R 1}, \delta_{S 1}$, respectively.

Similarly, the average reliability under the performance target can be evaluated by

$$
\begin{aligned}
\beta_{2} & =\frac{\ln \left(\left(\mu_{R 2} / \mu_{S 2}\right) \sqrt{\left(1+\delta_{S 2}^{2}\right) /\left(1+\delta_{R 2}^{2}\right)}\right)}{\sqrt{\ln \left[\left(1+\delta_{R 2}^{2}\right)\left(1+\delta_{S 2}^{2}\right)\right]}} \\
& =\frac{\ln \left(\mu_{R 2} / \mu_{S 2}\right)}{\sqrt{\ln \left[\left(1+\delta_{R 2}^{2}\right)\left(1+\delta_{S 2}^{2}\right)\right]}},
\end{aligned}
$$

where meanings of parameters follow (6).
For one performance target, with the same material parameters, structural model, and seismic measures, deviation coefficients from FBD based on current Chinese codes will be consistent with that from DDBD. Thus, the relative reliability coefficient can be introduced by

$$
\alpha=\frac{\beta_{2}}{\beta_{1}}=\frac{\ln \mu_{R 2}-\ln \mu_{S 2}}{\ln \mu_{R 1}-\ln \mu_{S 1}},
$$

where $\mu_{R 1}$ and $\mu_{S 1}$ are known. Adjusting $\alpha$ and $\mu_{R 2}$ by the proprietor, the average effect $\mu_{S 2}$ can be determined for DDBD, and errors from complex calculation of deviation coefficients will then be significantly avoided.

If there is the same performance level between FBD and $\operatorname{DDBD}\left(\mu_{R 1}=\mu_{R 2}\right)$, taking $\alpha=1$, thus $\mu_{S 1}=\mu_{S 2}$. That means under frequent earthquake risk the maximum story drift ratio at the performance point from DDBD equals that from FBD. In this paper, we mainly discuss the case with $\alpha=1$.

2.2. Section Bearing Capacity Equation. Structural reliability depends on the expression of section bearing capacity and the seismic measures. Theoretically, once the concept of mode decomposition is introduced to $\mathrm{DDBD}[21,22]$ or the profile used to decide the ESDOF is very close to the really reacting profile, the calculated base shear of structure under frequent earthquake risk from both DDBD and FBD is the same, due to the basic assumptions of ESDOF. Therefore, to ensure that the relative reliability in DDBD equals the designed reliability in FBD, only the same expression of section bearing capacity and seismic measures are required. That is,

$$
S=\gamma_{G} S_{G E}+\gamma_{E h} S_{E h k} \leq \frac{R}{\gamma_{R E}} .
$$

2.3. Design Procedures of Relative Reliability Approach for $D D B D$. The design steps of relative reliability approach for DDBD are given as follows:

(1) Determine the performance target of structure according to the proprietor.

(2) Preliminary design: determine the structural arrangement, section dimension, material strength and load action, and so forth.

(3) Evaluate the average resistance $\mu_{R 1}$ corresponding to the performance target from FBD and the average effect $\mu_{S 1}$ corresponding to the performance point under frequent earthquake risk (by a common database established by statistical analysis).

(4) Based on the performance target, determine the relative reliability coefficient $\alpha$ and the average resistance $\mu_{R 2}$ from DDBD.

(5) Determine the designed displacement $\mu_{S 2}$ using (8).

(6) Determine the equivalent parameters of the equivalent single degree of freedom system (ESDOF) for DDBD (for tall frames the method of mode decomposition should be used [21, 22]).

(7) Calculate the base shear and seismic forces in DDBD. 
TABLE 1: Basic parameters of PPC frames.

\begin{tabular}{|c|c|c|c|c|c|c|}
\hline $\begin{array}{l}\text { Number of } \\
\text { frames }\end{array}$ & $\begin{array}{c}\text { Site } \\
\text { category }\end{array}$ & $\begin{array}{c}\text { Number of } \\
\text { spans }\end{array}$ & $\begin{array}{c}\text { Fortification } \\
\text { intensity }\end{array}$ & $\begin{array}{c}\text { Number of } \\
\text { stories }\end{array}$ & $\begin{array}{c}\text { Total } \\
\text { height }(\mathrm{m})\end{array}$ & Seismic level \\
\hline YKJ-1 & II & 2 & 7-degree $0.1 \mathrm{~g}$ & 4 & 20.4 & 3 \\
\hline YKJ-2 & II & 2 & 8-degree $0.2 \mathrm{~g}$ & 4 & 20.4 & 2 \\
\hline YKJ-3 & II & 2 & 8-degree $0.2 \mathrm{~g}$ & 3 & 15.6 & 2 \\
\hline YKJ-4 & II & 2 & 7-degree $0.1 \mathrm{~g}$ & 3 & 15.6 & 3 \\
\hline YKJ-5 & II & 2 & 7-degree $0.1 \mathrm{~g}$ & 5 & 25.2 & 2 \\
\hline YKJ-6 & II & 2 & 8-degree $0.2 \mathrm{~g}$ & 5 & 25.2 & 1 \\
\hline YKJ-7 & II & 2 & 7-degree $0.1 \mathrm{~g}$ & 7 & 34.8 & 2 \\
\hline YKJ-8 & II & 2 & 8 -degree $0.2 \mathrm{~g}$ & 7 & 34.8 & 1 \\
\hline YKJ-9 & II & 3 & 7-degree $0.1 \mathrm{~g}$ & 7 & 34.8 & 2 \\
\hline YKJ-10 & II & 3 & 8-degree $0.2 \mathrm{~g}$ & 7 & 34.8 & 1 \\
\hline YKJ-11 & II & 3 & 7-degree $0.1 \mathrm{~g}$ & 5 & 25.2 & 2 \\
\hline YKJ-12 & II & 3 & 8-degree $0.2 \mathrm{~g}$ & 5 & 25.2 & 1 \\
\hline YKJ-13 & II & 3 & 7-degree $0.1 \mathrm{~g}$ & 4 & 20.4 & 3 \\
\hline YKJ-14 & II & 3 & 8-degree $0.2 \mathrm{~g}$ & 4 & 20.4 & 2 \\
\hline YKJ-15 & II & 3 & 7-degree $0.1 \mathrm{~g}$ & 3 & 15.6 & 3 \\
\hline YKJ-16 & II & 3 & 8 -degree $0.2 \mathrm{~g}$ & 3 & 15.6 & 2 \\
\hline YKJ-17 & III & 2 & 7-degree $0.1 \mathrm{~g}$ & 4 & 20.4 & 3 \\
\hline YKJ-18 & III & 2 & 8-degree $0.2 \mathrm{~g}$ & 4 & 20.4 & 2 \\
\hline YKJ-19 & III & 2 & 7-degree $0.1 \mathrm{~g}$ & 7 & 34.8 & 2 \\
\hline YKJ-20 & III & 2 & 8 -degree $0.2 \mathrm{~g}$ & 7 & 34.8 & 1 \\
\hline YKJ-21 & III & 3 & 7-degree $0.1 \mathrm{~g}$ & 7 & 34.8 & 2 \\
\hline YKJ-22 & III & 3 & 8-degree $0.2 \mathrm{~g}$ & 7 & 34.8 & 1 \\
\hline YKJ-23 & III & 3 & 7-degree $0.1 \mathrm{~g}$ & 4 & 20.4 & 3 \\
\hline YKJ-24 & III & 3 & 8-degree $0.2 \mathrm{~g}$ & 4 & 20.4 & 2 \\
\hline
\end{tabular}

(8) Use the same expression of section bearing capacity as in current Chinese codes for reinforcement design.

(9) Conduct the deformation capacity design and seismic measures design.

Given this paper is a part of the team's research on the prestressed frame, the subject of this paper is the partial prestressed frame. However, there is no essential difference between the proposed DDBD procedures for ordinary frame and for PPRC frame.

Specifically, the main differences of the proposed DDBD procedure for PPRC frame are as follows:

(1) The prestressed reinforcements are determined in preliminary design (step 2) and not changed in the following process.

(2) In the process of determining the target displacement (from step 3 to step 5), the reference displacement demands are the displacement demands of PPRC frames under the same earthquake risk.

(3) After the base shear of DDBD is derived and the design force of the sections is determined, the design of sections, the seismic measures, and details of seismic design all follow the rules for PPRC frame in the codes of China.

\subsection{Selection of Parameters in DDBD}

2.4.1. Average Seismic Effect under Frequent Earthquake Risk of Current Chinese Codes. To verify the suggested relative reliability approach for DDBD, 24 PPC frames were first designed by FBD based on current Chinese codes, as shown in Table 1 . The average seismic effect $\mu_{S 1}$ was evaluated by the pushover analysis of these 24 PPC frames. Using capacity spectrum method, the average seismic effect (maximum story drift ratio at the performance point) under 7-degree fortification can be evaluated as 1/1399, while it can be evaluated as 1/850 under 8 -degree fortification [23].

2.4.2. Calculation of the Target Displacement in DDBD. With $\alpha=1$, then $\mu_{\mathrm{S} 1}=\mu_{\mathrm{S} 2}$. The target displacement $\left(\mu_{\mathrm{S} 2}\right)$ in DDBD is therefore $1 / 1399$ for 7 -degree fortification and 1/850 for 8-degree fortification. Since the given displacement target implies the average seismic effect of PPC frame structures under frequent earthquake risk of current Chinese codes, the discreteness of structural reliability will thus be decreased based on the suggested reliability approach. 
TABLE 2: Base shear comparison between force-based design and DDBD.

\begin{tabular}{|c|c|c|c|c|}
\hline Number of frames & $\begin{array}{c}\text { Base shear from } \\
\text { FBD }(\mathrm{kN})\end{array}$ & $\begin{array}{c}\text { Base shear from } \\
\text { DDBD }(\mathrm{kN})\end{array}$ & $\begin{array}{c}\text { Base shear }(\mathrm{FBD}) / \text { base } \\
\text { shear }(\mathrm{DDBD})\end{array}$ & Error \\
\hline YKJ-1 & 383.632 & 310.68 & 1.23 & $-19.02 \%$ \\
\hline YKJ-2 & 897.37 & 780.51 & 1.15 & $-13.02 \%$ \\
\hline YKJ-3 & 666.58 & 684.59 & 0.97 & $2.70 \%$ \\
\hline YKJ-4 & 342.81 & 290.31 & 1.18 & $-15.31 \%$ \\
\hline YKJ-5 & 464.48 & 363.24 & 1.28 & $-21.80 \%$ \\
\hline YKJ-6 & 1031.15 & 891.58 & 1.16 & $-13.54 \%$ \\
\hline YKJ-7 & 544.64 & 441.4 & 1.23 & $-18.96 \%$ \\
\hline YKJ-8 & 1188.89 & 983.03 & 1.21 & $-17.32 \%$ \\
\hline YKJ-9 & 834.33 & 676.5 & 1.23 & $-18.92 \%$ \\
\hline YKJ-10 & 1782.51 & 1482.73 & 1.20 & $-16.82 \%$ \\
\hline YKJ-11 & 693.87 & 545.57 & 1.27 & $-21.37 \%$ \\
\hline YKJ-12 & 1549.93 & 1394.74 & 1.11 & $-10.01 \%$ \\
\hline YKJ-13 & 561.615 & 419.65 & 1.34 & $-25.28 \%$ \\
\hline YKJ-14 & 1315.35 & 1132.17 & 1.16 & $-13.93 \%$ \\
\hline YKJ-15 & 493.85 & 404.59 & 1.22 & $-18.07 \%$ \\
\hline YKJ-16 & 1013.83 & 1034.08 & 0.98 & $2.00 \%$ \\
\hline YKJ-17 & 486.19 & 402.47 & 1.21 & $-17.22 \%$ \\
\hline YKJ-18 & 1136.12 & 985.24 & 1.15 & $-13.28 \%$ \\
\hline YKJ-19 & 690.2 & 566.92 & 1.22 & $-17.86 \%$ \\
\hline YKJ-20 & 1506.34 & 1239.11 & 1.22 & $-17.74 \%$ \\
\hline YKJ-21 & 1057.1 & 863.32 & 1.22 & $-18.33 \%$ \\
\hline YKJ-22 & 2258.44 & 1850.16 & 1.22 & $-18.08 \%$ \\
\hline YKJ-23 & 711.57 & 542.73 & 1.31 & $-23.73 \%$ \\
\hline YKJ-24 & 1666.55 & 1409.73 & 1.18 & $-15.41 \%$ \\
\hline Mean & & & 1.20 & $-15.85 \%$ \\
\hline
\end{tabular}

Note: error = (base shear from DDBD - base shear from FBD)/base shear from DDBD.

2.4.3. Modification of Section Bearing Capacity. Theoretically, the calculated base shear of structure under frequent earthquake risk from both DDBD and FBD is the same, due to the basic assumptions of ESDOF. However, inconsistence still exists due to the model errors of the DDBD method. To eliminate such errors in DDBD, the base shear derived from DDBD and from FBD has been compared by each example of 24 PPC frames, as shown in Table 2.

Table 2 indicates that the maximum error of base shear from two methods is $25 \%$, while average error is around $16 \%$. Therefore, error correcting is required. A correction coefficient $\eta$ can be introduced to revise the expression of section bearing capacity for such error correcting. This coefficient $\eta$ is determined by the average ratio of base shear from $\mathrm{FBD}$ and from $\mathrm{DDBD}$, according to the numerical results of these $24 \mathrm{PPC}$ frames. The revised expression of section bearing capacity in DDBD is

$$
S=\gamma_{G} S_{G E}+\gamma_{E h} \eta S_{E h k} \leq \frac{R}{\gamma_{R E}}
$$

where $\eta=1.20$.

\section{Numerical Analysis}

3.1. Basic Information. To verify the effectiveness of the suggested relative reliability approach for DDBD, 10 PPC frames were tested. Aimed at the performance target of "being intact after frequent earthquakes," the structure was designed by the relative reliability approach for DDBD (with the same material properties, dimensions of members used in FBD based on current Chinese codes). Subsequently, the reliability level at both "being intact after frequent earthquakes" and "not collapsed after rare earthquakes" based on DDBD was compared with that from FBD.

The basic information of 10 examples is shown in Table 3. For all 10 examples, let the relative reliability coefficient be unit $(\alpha=1)$. That means the reliability level was selected to be consistent with the average reliability in current Chinese codes. As $\alpha=1$, once the reliability corresponding to the performance target of "not collapsed after rare earthquakes" is transformed to the nominal reliability of "life safety under frequent earthquake risk," the target displacement is equal to that of "being intact after frequent earthquakes," which can be obtained simultaneously. The target displacements were adopted as in Section 2.4.2. 
TABLE 3: Basic parameters of 10 PPC frames.

\begin{tabular}{|c|c|c|c|c|c|c|}
\hline Number of frames & Site category & Number of spans & Fortification intensity & Number of stories & Total height (m) & Seismic level \\
\hline YKJ-1 & II & 2 & 7-degree $0.1 \mathrm{~g}$ & 4 & 20.4 & 3 \\
\hline YKJ-2 & II & 2 & 8 -degree $0.2 \mathrm{~g}$ & 4 & 20.4 & 2 \\
\hline YKJ-7 & II & 2 & 7-degree $0.1 \mathrm{~g}$ & 7 & 34.8 & 2 \\
\hline YKJ-8 & II & 2 & 8 -degree $0.2 \mathrm{~g}$ & 7 & 34.8 & 1 \\
\hline YKJ-9 & II & 3 & 7-degree $0.1 \mathrm{~g}$ & 7 & 34.8 & 2 \\
\hline YKJ-10 & II & 3 & 8-degree $0.2 \mathrm{~g}$ & 7 & 34.8 & 1 \\
\hline YKJ-13 & II & 3 & 7-degree $0.1 \mathrm{~g}$ & 4 & 20.4 & 3 \\
\hline YKJ-14 & II & 3 & 8 -degree $0.2 \mathrm{~g}$ & 4 & 20.4 & 2 \\
\hline YKJ-19 & III & 2 & 7-degree $0.1 \mathrm{~g}$ & 7 & 34.8 & 2 \\
\hline YKJ-20 & III & 2 & 8 -degree $0.2 \mathrm{~g}$ & 7 & 34.8 & 1 \\
\hline
\end{tabular}

TABLE 4: Performance point coordinates and related parameters of frame designed according to DDBD under frequent earthquake risk.

\begin{tabular}{|c|c|c|c|c|c|}
\hline Number of frames & $\begin{array}{l}\text { Performance point } \\
\qquad\left(S_{d}, S_{a}\right)\end{array}$ & $\begin{array}{l}\text { Performance point } \\
\qquad\left(V_{b}, u_{t}\right)\end{array}$ & $\begin{array}{l}\text { Story drift ratio of } \\
\text { performance point }\end{array}$ & Target drift ratio & Relative error \\
\hline YKJ-1 & $(0.00946,0.3081)$ & $(277.10,0.01139)$ & $1 / 1330$ & $1 / 1399$ & $4.93 \%$ \\
\hline YKJ-2 & $(0.01538,0.7411)$ & $(679.72,0.01853)$ & $1 / 826$ & $1 / 850$ & $2.82 \%$ \\
\hline YKJ-7 & $(0.01271,0.2370)$ & $(368.04,0.01585)$ & $1 / 1733$ & $1 / 1399$ & $-19.3 \%$ \\
\hline YKJ-8 & $(0.02148,0.5505)$ & $(873.99,0.02680)$ & $1 / 969$ & $1 / 850$ & $-14.0 \%$ \\
\hline YKJ-9 & $(0.01193,0.2506)$ & $(579.10,0.01488)$ & $1 / 1827$ & $1 / 1399$ & $-23.4 \%$ \\
\hline YKJ-10 & $(0.02089,0.5642)$ & $(1328.4,0.02610)$ & $1 / 995$ & $1 / 850$ & $-17.0 \%$ \\
\hline YKJ-13 & $(0.01000,0.2933)$ & $(390.00,0.01204)$ & $1 / 1226$ & $1 / 1399$ & $12.4 \%$ \\
\hline YKJ-14 & $(0.01523,0.7473)$ & $(1009.6,0.01835)$ & $1 / 821$ & $1 / 850$ & $3.41 \%$ \\
\hline YKJ-19 & $(0.01626,0.2975)$ & $(461.99,0.02028)$ & $1 / 1383$ & $1 / 1399$ & $1.14 \%$ \\
\hline YKJ-20 & $(0.02714,0.6991)$ & $(1109.9,0.03387)$ & $1 / 769$ & $1 / 850$ & $9.53 \%$ \\
\hline
\end{tabular}

Note: relative error $=($ story drift ratio of performance point - target drift ratio $)$ /story drift ratio of performance point.

As all these examples are regular PPC frames with total height less than $40 \mathrm{~m}$, it is reasonably assumed that the first mode of vibration will dominate the structural response during the analysis. Numerical results for performance points and reliability indices are shown in the following sections.

3.2. Results of Pushover Analysis. Tables 4 and 5 list the parameters corresponding to performance points of pushover analysis, based on DDBD under frequent earthquake risk and rare earthquake risk, respectively.

As shown in the last column of Table 4, for this group of 10 PPC frames, the maximum relative errors between the target displacement and the maximum story drift ratio at the performance point under frequent earthquake risk are $23.4 \%$, while most of the rest is below $10 \%$. Therefore, it is believable that the suggested approach can provide an effective target displacement for DDBD.

3.3. Reliability Indices under Performance Target. If the effect was defined by the maximum story drift ratio at the performance point of the expected earthquake, while the resistance was represented by the maximum story drift ratio corresponding to the expected performance level, the reliability indices for each performance level can be calculated (as shown in Tables 6 and 7, where the deviation coefficients from FBD and from DDBD are the same).

The average reliability indices from FBD between the performance level of "being intact after frequent earthquakes" and the performance level of "not collapsed after rare earthquakes" are 2.517 and 0.669 [23], respectively. To clearly express the change of reliability, the values of reliability indices from DDBD and from FBD were also compared in Figures 2 and 3, for frequent earthquake risk and rare earthquake risk, respectively.

The triangular points shown in Figures 2 and 3 represent the mean of reliability under current Chinese design codes.

Comparing results in Figure 2 with Figure 3, the reliability from DDBD corresponding to the performance level is much closer to the mean of structural reliability from current Chinese codes, indicating that the design is more reasonable, and the suggested relative reliability approach for DDBD is effective and superior. However, it is also observed that the trend of current reliability towards the average reliability did not reach an expected level. Probable reasons include the following:

(1) The reinforcement design of a structure may not be dominated by the seismic effect. Seismic design of PPC frames is strongly dependent on the anticrack measures and seismic measures. 
TABLE 5: Performance point coordinates and related parameters of frame designed according to DDBD under rare earthquake risk.

\begin{tabular}{lccc}
\hline Number of frames & $\begin{array}{c}\text { Performance point } \\
\left(S_{d}, S_{a}\right)\end{array}$ & $\begin{array}{c}\text { Performance point } \\
\left(V_{b}, u_{t}\right)\end{array}$ & $\begin{array}{r}\text { Story drift angle of } \\
\text { performance point }\end{array}$ \\
\hline YKJ-1 & $(0.06463,1.361)$ & $(1223.9,0.07784)$ & $1 / 160$ \\
YKJ-2 & $(0.10150,2.501)$ & $(2293.9,0.12230)$ & $1 / 111$ \\
YKJ-7 & $(0.08813,1.158)$ & $(1798.3,0.10991)$ & $1 / 235$ \\
YKJ-8 & $(0.14140,2.109)$ & $(3348.3,0.17644)$ & $1 / 138$ \\
YKJ-9 & $(0.08282,1.241)$ & $(2868.0,0.10329)$ & $1 / 238$ \\
YKJ-10 & $(0.13840,2.175)$ & $(5120.8,0.17272)$ & $1 / 145$ \\
YKJ-13 & $(0.06858,1.256)$ & $(1670.1,0.08259)$ & $1 / 153$ \\
YKJ-14 & $(0.10080,2.580)$ & $(3485.5,0.12143)$ & $1 / 119$ \\
YKJ-19 & $(0.10710,1.273)$ & $(1976.9,0.13357)$ & $1 / 186$ \\
YKJ-20 & $(0.17800,2.505)$ & $(3977.0,0.22205)$ & $1 / 104$ \\
\hline
\end{tabular}

TABLE 6: The reliability index of 10 PPC frames under frequent earthquake.

\begin{tabular}{|c|c|c|c|c|c|c|c|}
\hline \multirow{2}{*}{$\begin{array}{l}\text { Number of } \\
\text { frames }\end{array}$} & \multirow{2}{*}{ Methods } & \multirow{2}{*}{$\begin{array}{l}\text { The design } \\
\text { base shear }\end{array}$} & \multicolumn{2}{|c|}{ Resistance $R$} & \multicolumn{2}{|c|}{ Effect $S$} & \multirow{2}{*}{$\begin{array}{l}\text { Reliability } \\
\text { index }\end{array}$} \\
\hline & & & $\begin{array}{l}\text { Story drift } \\
\text { ratio }\end{array}$ & $\begin{array}{l}\text { Coefficient } \\
\text { of variation }\end{array}$ & $\begin{array}{l}\text { Story drift } \\
\text { ratio }\end{array}$ & $\begin{array}{l}\text { Coefficient } \\
\text { of variation }\end{array}$ & \\
\hline \multirow{2}{*}{ YKJ-1 } & DDBD & 373.092 & $1 / 486$ & 0.22 & $1 / 1330$ & 0.31 & 2.760 \\
\hline & FBD & 383.632 & $1 / 480$ & 0.22 & $1 / 1398$ & 0.31 & 2.927 \\
\hline \multirow{2}{*}{ YKJ-2 } & DDBD & 905.484 & $1 / 482$ & 0.22 & $1 / 826$ & 0.31 & 1.504 \\
\hline & FBD & 897.370 & $1 / 517$ & 0.22 & $1 / 883$ & 0.31 & 1.495 \\
\hline \multirow{2}{*}{ YKJ-7 } & DDBD & 420.360 & $1 / 609$ & 0.22 & $1 / 1733$ & 0.31 & 2.864 \\
\hline & FBD & 544.640 & $1 / 578$ & 0.22 & $1 / 1814$ & 0.31 & 3.127 \\
\hline \multirow{2}{*}{ YKJ-8 } & DDBD & 1022.93 & $1 / 320$ & 0.22 & $1 / 969$ & 0.31 & 2.811 \\
\hline & FBD & 1188.89 & $1 / 311$ & 0.22 & $1 / 998$ & 0.31 & 3.187 \\
\hline \multirow{2}{*}{ YKJ-9 } & DDBD & 625.572 & $1 / 655$ & 0.22 & $1 / 1827$ & 0.31 & 2.811 \\
\hline & FBD & 834.330 & $1 / 587$ & 0.22 & $1 / 1875$ & 0.31 & 3.174 \\
\hline \multirow{2}{*}{ YKJ-10 } & DDBD & 1516.80 & $1 / 360$ & 0.22 & $1 / 995$ & 0.31 & 2.786 \\
\hline & $\mathrm{FBD}$ & 1782.51 & $1 / 367$ & 0.22 & $1 / 1017$ & 0.31 & 2.793 \\
\hline \multirow{2}{*}{ YKJ-13 } & DDBD & 551.832 & $1 / 438$ & 0.22 & $1 / 1226$ & 0.31 & 2.820 \\
\hline & FBD & 561.615 & $1 / 402$ & 0.22 & $1 / 1263$ & 0.31 & 3.130 \\
\hline \multirow{2}{*}{ YKJ-14 } & DDBD & 1334.77 & $1 / 448$ & 0.22 & $1 / 821$ & 0.31 & 1.684 \\
\hline & FBD & 1315.35 & $1 / 478$ & 0.22 & $1 / 868$ & 0.31 & 1.66 \\
\hline \multirow{2}{*}{ YKJ-19 } & DDBD & 657.432 & $1 / 562$ & 0.22 & $1 / 1383$ & 0.31 & 2.475 \\
\hline & FBD & 690.200 & $1 / 568$ & 0.22 & $1 / 1454$ & 0.31 & 2.581 \\
\hline \multirow{2}{*}{ YKJ-20 } & DDBD & 1599.89 & $1 / 311$ & 0.22 & $1 / 770$ & 0.31 & 2.491 \\
\hline & FBD & 1506.34 & $1 / 309$ & 0.22 & $1 / 783$ & 0.31 & 2.553 \\
\hline
\end{tabular}

(2) The lateral displacement mode of DDBD in this paper is based on the cantilever mode [6], while in FBD of current Chinese codes the lateral displacement mode is based on the inversed triangular load distribution pattern. Different displacement modes produce different analysis results. Let YKJ-2 be an example. The base shear from FBD is $897 \mathrm{kN}$, with the seismic force for each level being $91.4 \mathrm{kN}, 162.6 \mathrm{kN}, 234.9 \mathrm{kN}$, and $408.3 \mathrm{kN}$, respectively, while the base shear from DDBD is $905 \mathrm{kN}$, with the seismic force from level 1 to level 4 being $128.4 \mathrm{kN}, 213.2 \mathrm{kN}, 273.5 \mathrm{kN}$, and $290.4 \mathrm{kN}$, respectively.
(3) Current approach of DDBD is directly based on Priestley's work [2], where the complicate real structure is simplified to an ESDOF for the calculation of equivalent stiffness and base shear. Such simplification undoubtedly leads to obvious errors of calculation. In view of the development of DDBD, a more accurate theory is needed, which is not restricted by Priestley's traditional ESDOF model, and a more stable and reliable method is need to decide the seismic effects. Therefore, once breakthroughs can be achieved on this, the potential of DDBD will be great. 
TABLE 7: The reliability index of 10 PPC frames under rare earthquake.

\begin{tabular}{|c|c|c|c|c|c|c|}
\hline \multirow{2}{*}{$\begin{array}{l}\text { Number of } \\
\text { frames }\end{array}$} & \multirow{2}{*}{ Methods } & \multicolumn{2}{|c|}{ Resistance $R$} & \multicolumn{2}{|c|}{ Effect $S$} & \multirow{2}{*}{$\begin{array}{c}\text { Reliability } \\
\text { index }\end{array}$} \\
\hline & & $\begin{array}{l}\text { Story drift } \\
\text { ratio }\end{array}$ & $\begin{array}{l}\text { Coefficient of } \\
\text { variation }\end{array}$ & $\begin{array}{l}\text { Story drift } \\
\text { ratio }\end{array}$ & $\begin{array}{l}\text { Coefficient } \\
\text { of variation }\end{array}$ & \\
\hline \multirow{2}{*}{ YKJ-1 } & DDBD & $1 / 116.5$ & 0.359 & $1 / 160$ & 0.407 & 0.636 \\
\hline & FBD & $1 / 116$ & 0.359 & $1 / 169$ & 0.407 & 0.749 \\
\hline \multirow{2}{*}{ YKJ-2 } & DDBD & $1 / 98$ & 0.359 & $1 / 111$ & 0.407 & 0.268 \\
\hline & FBD & $1 / 93$ & 0.359 & $1 / 120$ & 0.407 & 0.517 \\
\hline \multirow{2}{*}{ YKJ-7 } & DDBD & $1 / 117$ & 0.359 & $1 / 235$ & 0.407 & 1.362 \\
\hline & FBD & $1 / 115$ & 0.359 & $1 / 248$ & 0.407 & 1.497 \\
\hline \multirow{2}{*}{ YKJ-8 } & DDBD & $1 / 101$ & 0.359 & $1 / 138$ & 0.407 & 0.632 \\
\hline & FBD & $1 / 101$ & 0.359 & $1 / 136$ & 0.407 & 0.598 \\
\hline \multirow{2}{*}{ YKJ-9 } & DDBD & $1 / 120$ & 0.359 & $1 / 238$ & 0.407 & 1.338 \\
\hline & FBD & $1 / 117$ & 0.359 & $1 / 252$ & 0.407 & 1.495 \\
\hline \multirow{2}{*}{ YKJ-10 } & DDBD & $1 / 106$ & 0.359 & $1 / 146$ & 0.407 & 0.642 \\
\hline & FBD & $1 / 103$ & 0.359 & $1 / 141$ & 0.407 & 0.630 \\
\hline \multirow{2}{*}{ YKJ-13 } & DDBD & $1 / 112$ & 0.359 & $1 / 153$ & 0.407 & 0.626 \\
\hline & FBD & $1 / 113$ & 0.359 & $1 / 164$ & 0.407 & 0.742 \\
\hline \multirow{2}{*}{ YKJ-14 } & DDBD & $1 / 93$ & 0.359 & $1 / 119$ & 0.407 & 0.501 \\
\hline & FBD & $1 / 94$ & 0.359 & $1 / 120$ & 0.407 & 0.497 \\
\hline \multirow{2}{*}{ YKJ-19 } & DDBD & $1 / 115$ & 0.359 & $1 / 186$ & 0.407 & 0.948 \\
\hline & FBD & $1 / 116$ & 0.359 & $1 / 193$ & 0.407 & 1.002 \\
\hline \multirow{2}{*}{ YKJ-20 } & DDBD & $1 / 99$ & 0.359 & $1 / 105$ & 0.407 & 0.143 \\
\hline & FBD & $1 / 102$ & 0.359 & $1 / 108$ & 0.407 & 0.139 \\
\hline
\end{tabular}

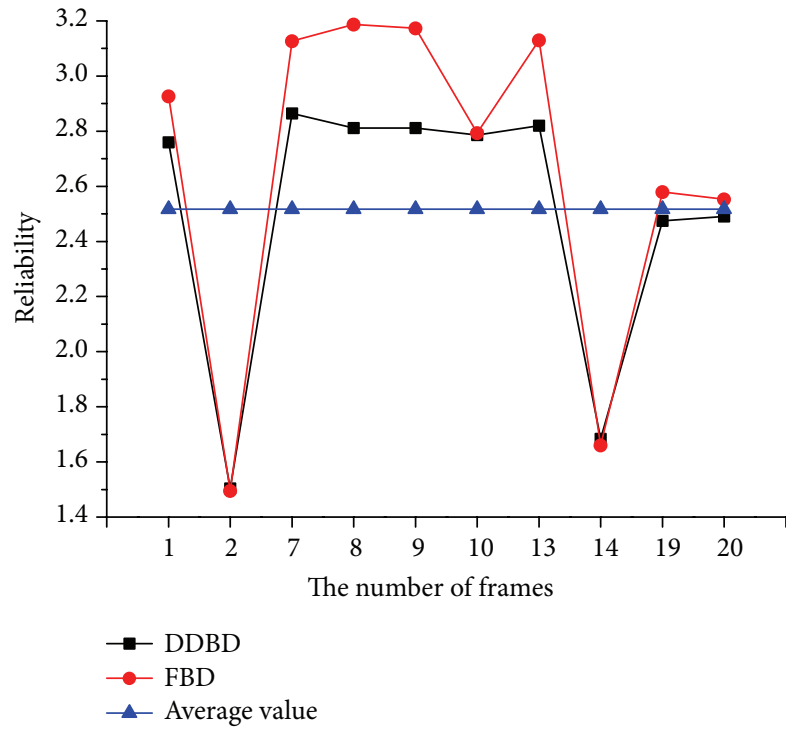

FIGURE 2: The contrast of the reliability index under frequent earthquake risk.

\section{Conclusions}

(1) Based on the average reliability level in current Chinese codes for the design of PPC frame structures, a relative reliability approach for DDBD is proposed.

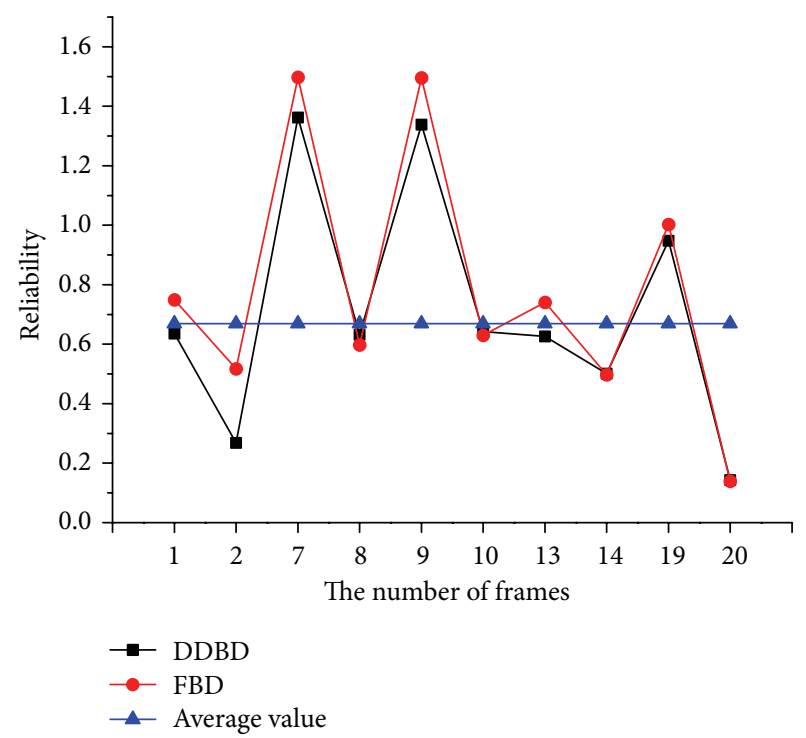

FIgURE 3: The contrast of the reliability index under rare earthquake risk.
The calculation of reliability at any performance level can be transformed to the nominal reliability of frequent earthquake for the expected earthquake risk level. In this approach, the displacement demand 
(maximum story drift ratio) under frequent earthquake risk is used as effect, while the maximum displacement (maximum story drift ratio) corresponding to the performance level is used as resistance. By introducing the relative reliability coefficient $\alpha$, the determination of the reliability from DDBD is transformed to the calculation of its ratio to the reliability from FBD, which not only follows the reliability principle implicit in current Chinese codes but also avoids the complex calculation of reliability in general.

(2) Based on the assumption of elasticity, if the displacement corresponding to the performance point of frequent earthquake from FBD was adopted as the target displacement in DDBD, the calculated base shear from FBD (mode decomposition method) will be equal to that from DDBD. Meanwhile, the error analysis was conducted between the base shear from DDBD and that from FBD, and a correction factor was suggested for calculation of the base shear in DDBD.

(3) Under frequent earthquake risk, the section bearing capacity for the suggested relative reliability approach for DDBD can also be expressed by the formula of section bearing capacity of FBD in current Chinese codes.

(4) The displacements of the PPC frames designed by the suggested relative reliability approach for DDBD are in effective control, and the reliability of the performance target is much closer to the mean of reliability in current Chinese codes. The suggested approach is verified to be effective and superior.

\section{Shortcomings in This Paper}

(1) A relative reliability approach for DDBD is first proposed in this paper; therefore, significant improvements of its theoretical framework are still required. The numerical examples for selection of parameters (such as target displacement) in the suggested approach are limited. The suggested approach is based on the bilinear model of ESDOF, which may seriously affect the calculation accuracy of DDBD.

(2) During the theoretical derivation, the structure is assumed in elasticity under frequent earthquake risk, which may make errors in reality. Towards this, a correction factor has been introduced in this paper to revise the base shear in DDBD.

(3) In this paper, the relative reliability approach for DDBD is introduced based on Chinese codes, but it is obvious that this approach can also be operable on the other codes.

\section{Conflict of Interests}

The authors declare that there is no conflict of interests regarding the publication of this paper.

\section{Acknowledgments}

This work was supported by "the Fundamental Research Funds for the Central Universities" of China (Grant no. 106112015CDJXY200004). The authors are grateful to Professor Hong Yang for enlightening discussions.

\section{References}

[1] M. J. Kowalsky, M. J. N. Priestley, and G. A. Macrae, "Displacement-based design of RC bridge columns in seismic regions," Earthquake Engineering and Structural Dynamics, vol. 24, no. 12, pp. 1623-1643, 1995.

[2] M. J. N. Priestley and M. J. Kowalsky, "Direct displacementbased seismic design of concrete buildings," Bulletin of the New Zealand National Society for Earthquake Engineering, vol. 33, no. 4, pp. 421-444, 2000.

[3] M. J. N. Priestley, G. M. Calvi, and M. J. Kowalsky, DisplacementBased Seismic Design of Structures, IUSS Press, Pavia, Italy, 2007.

[4] G. M. Calvi and T. J. Sullivan, Eds., A Model Code for the Displacement-Based Seismic Design of Structures, DBD09, DRAFT Subject to Public Enquiry, IUSS Press, Pavia, Italy, 2009.

[5] T. J. Sullivan, M. J. N. Priestley, and G. M. Calvi, Eds., A Model Code for the Displacement-Based Seismic Design of Structures, DBD12, IUSS Press, 2012.

[6] X. W. Liang, Y. J. Huang, and Q. W. Yang, "Displacement-based seismic design method of RC frames," China Civil Engineering Journal, vol. 38, no. 9, pp. 53-60, 2005.

[7] R. Garcia, T. J. Sullivan, and G. D. Corte, "Development of a displacement-based design method for steel frame-RC wall buildings," Journal of Earthquake Engineering, vol. 14, no. 2, pp. 252-277, 2010.

[8] D. Zonta, C. Loss, M. Piazza, and P. Zanon, "Direct displacement-based design of glulam timber frame buildings," Journal of Earthquake Engineering, vol. 15, no. 3, pp. 491-510, 2011.

[9] T. J. Sullivan, "Direct displacement-based seismic design of steel eccentrically braced frame structures," Bulletin of Earthquake Engineering, vol. 11, no. 6, pp. 2197-2231, 2013.

[10] S. Malekpour and F. Dashti, "Application of the direct displacement based design methodology for different types of RC structural systems," International Journal of Concrete Structures and Materials, vol. 7, no. 2, pp. 135-153, 2013.

[11] C. J. Wei, L. Wei, and X. W. Gao, "Seismic reliability analysis of structure based upon limit elasto-plastic story drift," Engineering Mechanics, vol. 3, no. 1, pp. 60-70, 1986.

[12] X. W. Gao and J. M. Shen, "A seismic reliabilty analysis of deformation capacity for reinforced concrete frame structure under 'major earthquake,' China Civil Engineering Journal, vol. 26, no. 3, pp. 3-12, 1993.

[13] R. D. Bertero and V. V. Bertero, "Performance-based seismic engineering: the need for a reliable conceptual comprehensive approach," Earthquake Engineering \& Structural Dynamics, vol. 31, no. 3, pp. 627-652, 2002.

[14] B. Wu and Y.-H. Li, "Reliability level of interstory drift for weak story of existing RC frame structure," Journal of Earthquake Engineering and Engineering Vibration, vol. 23, no. 6, pp. $103-$ 108, 2003.

[15] M. Montiel and A. Teran-Gilmore, "Comparative reliability of two 24-story braced buildings: traditional versus innovative," Structural Design of Tall and Special Buildings, vol. 22, no. 8, pp. 635-654, 2013. 
[16] T. J. Sullivan, D. P. Welch, and G. M. Calvi, "Simplified seismic performance assessment and implications for seismic design," Earthquake Engineering and Engineering Vibration, vol. 13, supplement 1, pp. 95-122, 2014.

[17] D. P. Welch, T. J. Sullivan, and G. M. Calvi, "Developing direct displacement-based procedures for simplified loss assessment in performance-based earthquake engineering," Journal of Earthquake Engineering, vol. 18, no. 2, pp. 290-322, 2014.

[18] National Standard of the People's Republic of China, Code for Seismic Design of Buildings, China Architecture and Building Press, Beijing, China, 2010.

[19] National Standard of the People's Republic of China, Technical Specification for Concrete Structures of Tall Building, JGJ3-2010, China Architecture and Building Press, Beijing, China, 2010.

[20] G. B. Wang, Study on the Parameters Related to Direct Displacement-Based Seismic Design Approach of Partially Prestressed Concrete Frame Structures, Chongqing University, Chongqing, China, 2012.

[21] A. K. Chopra and R. K. Goel, "A modal pushover analysis procedure for estimating seismic demands for buildings," Earthquake Engineering \& Structural Dynamics, vol. 31, no. 3, pp. 561-582, 2002.

[22] L. Xin and X. W. Liang, "Direct displacement-based seismic design method of high-rise buildings," Industrial Construction, vol. 38, no. 7, pp. 6-10, 2008.

[23] P. P. Liao, Study on the theory of direct displacement-based seismic design for partially prestressed concrete frame based on relative reliability concept [M.S. thesis], Chongqing University, Chongqing, China, 2014. 


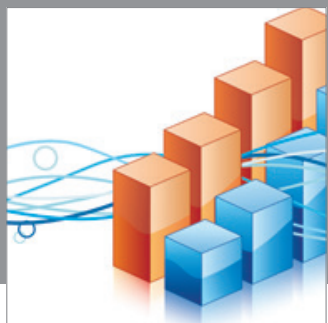

Advances in

Operations Research

mansans

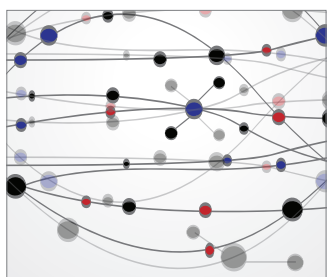

The Scientific World Journal
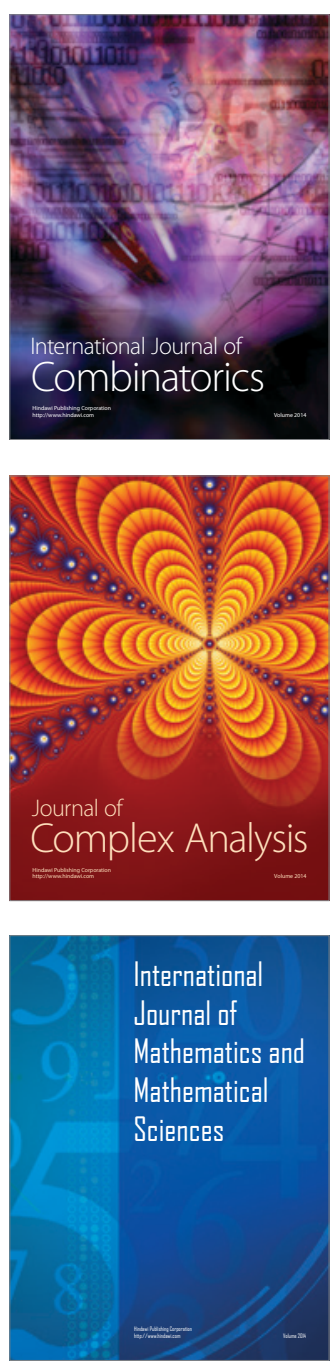
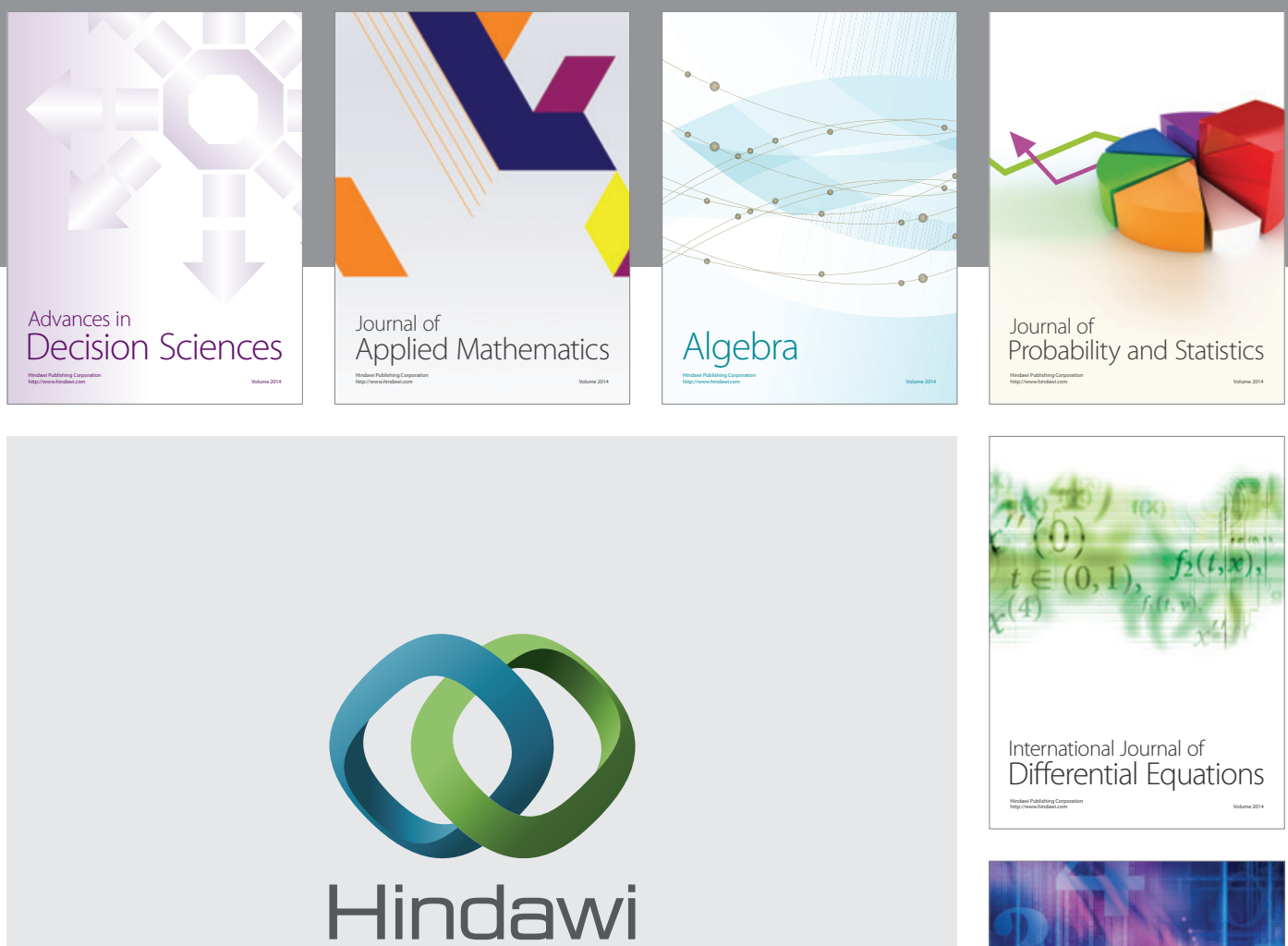

Submit your manuscripts at http://www.hindawi.com
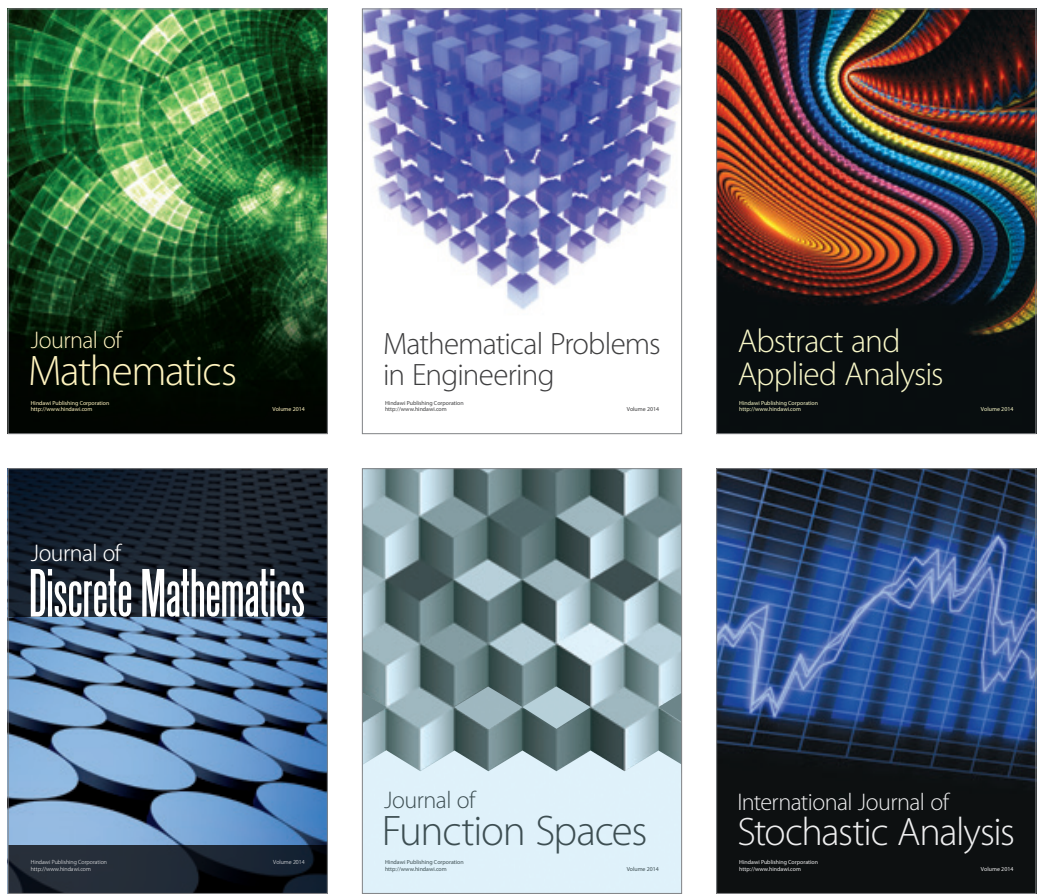

Journal of

Function Spaces

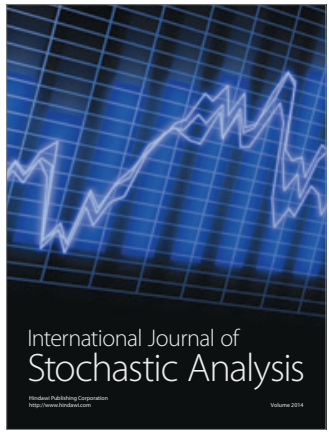

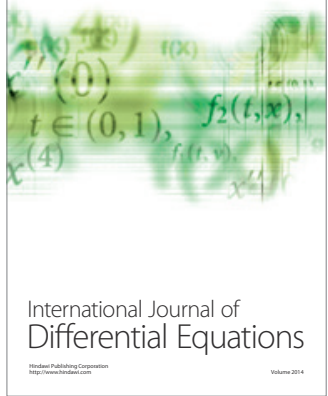
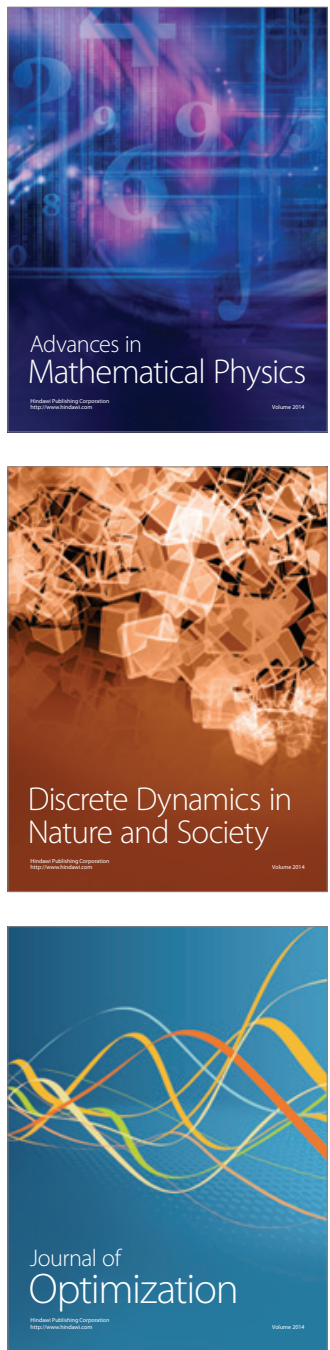